\title{
Determinan Purchase intention: Perspektif Pelanggan Minimarket
}

\author{
Hendika Rizkianti* \\ Program Studi Manajemen.Universitas Trisakti \\ Jalan Kyai Tapa No. 1 Grogol, Jakarta Barat, Indonesia \\ hendikarizki07@gmail.com \\ Kurniawati \\ Program Studi Manajemen.Universitas Trisakti \\ Jalan Kyai Tapa No. 1 Grogol, Jakarta Barat, Indonesia \\ kurniawati@trisakti.ac.id
}

Diterima: 09-02-2021

Disetujui: 16-06-2021

Dipublikasi: 30-06-2021

\begin{abstract}
ABSTRAK
Tujuan dalam penelitian yaitu untuk menganalisis pengaruh brand awareness, perceived quality, brand association, brand loyalty yang mempengaruhi purchase intention konsumen minimarket Alfamart, Indomaret, Lawson di Jakarta. Melakukan penyebaran kuesioner kepada 200 responden. Dalam penelitian ini pegambilan sampel menggunakan non-probabilitas sampling, pada penelitian ini menggunakan purposive sampling. Metode analisis data menggunakan structural equation modeling (SEM) dan software AMOS22. Hasil menampilkan variabel brand awareness, perceived quality,mempengaruhi positif terhadap purchase intention tidak didukung. Kemudian brand association, brand loyalty mempengaruhi positif juga signifikan terhadap purchase intention minimarket Alfamart, Indomaret, Lawson di Jakarta. Adapun saran buat manajemen minimarket Alfamart, Indomaret, Lawson di Jakarta dalam meningkatkan brand awareness, perceived quality, perusahaan yang dapat mempengaruhi purchase intention konsumen pada minimarket Alfamart, Indomaret, Lawson di Jakarta.
\end{abstract}

Kata Kunci:

Brand association; Brand Loyalty; Purchase intention.

\section{ABSTRACT}

The purpose of this research is to analyze the effect of brand awareness, perceived quality, brand association, and brand loyalty which affect the purchase intention of consumers at Alfamart minimarkets, Indomaret, Lawson in Jakarta. Distributing questionnaires to 200 respondents. In this study, sampling using non-probability sampling, in this study using purposive sampling. The data analysis method uses structural equation modeling (SEM) and AMOS22 software. The results show that the variable brand awareness, perceived quality, has a positive effect on purchase intention is not supported. Then brand association, brand loyalty also has a significant positive effect on the purchase intention of Alfamart, Indomaret, Lawson minimarkets in Jakarta. As for suggestions for the management of Alfamart minimarkets, Indomaret, Lawson in Jakarta in increasing brand awareness, perceived quality, companies that can influence consumer purchase intention at Alfamart minimarkets, Indomaret, Lawson in Jakarta.

Keywords:

Brand association; Brand Loyalty; Purchase intention 


\section{PENDAHULUAN}

Masa modern sekarang sangat mempermudah konsumen buat penuhi kebutuhan hidup tiap hari. Minimarket sebagai salah satu opsi yang maksimal untuk konsumen, dimana dalam minimarket sediakan barang kebutuhan tiap hari serta mempermudah konsumen mencari produk bermutu, minimarket juga memiliki layanan pembayaran semacam: Listrik, air, tagihan internet, transfer bank, sehingga perihal ini bisa mempermudah konsumen yang mau membayar dengan metode yang segera serta aman (Le-Hoang et,al., 2020). Persebaran minimarket di Indonesia menunjukkan adanya pertumbuhan ekonomi yang tinggi. Di Indonesia ada beberapa minimarket yang memiliki omset penjualan terbesar yaitu seperti Indomaret pada tahun 2018 mencapai Rp 73,73 triliun naik sebesar 16\% dari tahun 2017 sedangkan pada tahun 2019 omsetnya mencapai Rp 80 triliun, disusul oleh Alfamart pada tahun 2017 mencapai omset Rp 61,46 triliun dan selama 2018 meningkat sebesar Rp 66,82 triliun. Sementara itu minimarket Lawson masih akan terus mengembangkan minimarket Lawson di wilayah Jabodetabek dan Bali.

Dalam ketatnya persaingan perputaran penjualan di minimarket membuat peneliti tertarik untuk melaksanakan penelitian ini, serta ingin menampilkan variabel mana yang mempengaruhi purchase intention pelanggan minimarket alfamart, indomaret \& Lawson di Jakarta. (Gumiwang, 2019; Tristiawati, 2019). Purchase intention menampilkan kalau konsumen hendak merancang ataupun bersedia membeli produk ataupun layanan tertentu di masa mendatang. (Chinomona \& Maziriri, 2017; Yaseen \& Mazahir, 2019). Selanjutnya, konsumen dapat dengan mudah beralih ke minimarket lain, yang menjadi tantangan bagaimana pengelolaan minimarket menunjukkan keunikan dan perbedaannya dari minimarket lain.

Keunikan yang tinggi dari suatu produk akan membawa identitas yang tinggi, brand awareness konsumen dan asosiasi merek (Le-Hoang et al., 2020). Lalu brand awareness jua mempengaruhi purchase intention pelanggan minimarket. Konsumen biasanya membeli merek yang mereka kenal, jadi meningkatkan kesadaran merek sangat penting untuk bisnis. Peningkatan brand awareness dapat dilakukan dengan meningkatkan strategi pemasaran merek dengan sosial media yaitu Facebook, Twitter dan Instagram.

Perceived quality konsumen terhadap kinerja minimarket dengan minimarket lain juga dapat mempengaruhi purchase intention konsumen di minimarket, yang juga dapat menimbulkan loyalitas konsumen terhadap merek (Gil-Saura et al., 2013; Horng et,al., 2012; Khan et,al., 2014). Keputusan pembelian konsumen juga dipengaruhi oleh asosiasi merek, dimana semakin tinggi asosiasi merek maka akan semakin tinggi kesukaan dan keterikatan konsumen terhadap merek tersebut. (Susilowati \& Sari, 2020). Hal ini menyebabkan munculnya persaingan ketat perusahaan minimarket untuk memikat konsumen dan memenuhi kepuasan konsumen.

Kepuasan hanya terjadi jika kinerja merek yang sebenarnya melebihi ekspetasi konsumen. Sehingga menjaga dan mengembangkan kepuasan konsumen terhadap merek menjadi misi penting bagi 
bisnis. Oleh karena itu, jaringan minimarket perlu mengetahui dimana kekuatan dan kelemahan agar dapat mengambil tindakan yang tepat. (Le-Hoang et al., 2020)

Rumusan masalah pada studi ini: (1) Apakah ada pengaruh positif brand awareness terhadap purchase intention? (2) Apakah ada pengaruh positif perceived quality terhadap purchase intention? (3) Apakah ada pengaruh positif brand association terhadap purchase intention? (4) Apakah ada pengaruh positif brand loyalty terhadap purchase intention?

\section{Brand awareness}

Brand awareness merupakan dimensi dari brand equity, brand awareness adalah kemampuan konsumen untuk sadar akan keberadaan suatu brand atau merek (Susilowati \& Sari, 2020). Konsumen akan cenderung membeli produk yang sudah mereka ketahui, sehingga tinggi brand awareness konsumen akan makin tinggi juga persepsi konsumen terhadap produk tersebut. Kesadaran merek terdiri dari dua bagian, yaitu ingatan merek dan kesadaran merek. Brand recall ialah kemampuan pelanggan buat ingat suatu brand, sedangkan identitas merek merupakan kemampuan pelanggan buat membedakan merek tertentu dibanding yang lain. Brand awareness yaitu bagaimana konsumen mengasosiasikan merek dengan produk tertentu yang mereka inginkan. (Sasmita \& Mohd Suki, 2015; Susilowati \& Sari, 2020)

Keahlian konsumen untuk mengidentifikasi sesuatu merk dalam sekian banyak permasalahan ialah hasil dari tingkatan kesadaran merek. Kesadaran merek memainkan kedudukan berarti dalam keputusan pembelian konsumen. Pemahaman merk merupakan campuran dari kognisi individu, kontrol pengetahuan serta memori merk (Chakraborty, 2019).

\section{Perceived quality}

Perceived quality ialah prasyarat berguna untuk membangun keterikatan emosional dari loyalitas serta keyakinan merk, yang didefinisikan bagaikan penilaian konsumen terhadap merk tertentu bersumber pada petunjuk internal serta eksternal (Atulkar, 2020; Rubio et al., 2017). Konsumen lebih menggemari merk bermutu besar sebab mencerminkan keandalan yang lebih besar serta membagikan sinyal positif. (Atulkar, 2020; Lin et al., 2017).

Perceived quality yakni sepanjang mana merk dianggap memberikan produk yang bermutu baik kepada konsumen. Perceived quality yang besar menampilkan kalau merk tersebut mempunyai keistimewaan serta mutu merk yang besar yang akhirnya pengaruhi konsumen buat membeli merk tersebut. (Chakraborty, 2019).

\section{Brand Assosiation}

Brand Assosiation merupakan segala hal yang dapat diperhatikan konsumen dari brand seperti karakteristik produk, keunikan, reputasi dan karakteristik nonfisik dari brand atau produk (Susilowati \& Sari, 2020), semakin tinggi brand assosiation pelanggan pada merek menyebabkan tinggi jua kesukaan pelanggan pada brand tersebut (Foroudi, Jin, Gupta, Foroudi, and Kitchen; 2018). Brand association menggambarkan sejauh mana konsumen memandang asosiasinya dengan merk. Tidak 
hanya itu, tingkatan asosiasi yang lebih besar menampilkan ikatan yang lebih kokoh antara konsumen serta merk.

Brand association mempunyai 3 komponen ialah (1) nilai yang dialami, merupakan komentar konsumen terhadap produk. Pembahasan atas komentar konsumen bisa pengaruhi nilai yang dialami dari produk yang bisa pengaruhi purchase intention konsumen, (2) Karakter merk, bisa bergantung bagaimana merek tersebut cocok dengan karakter konsumen. Karakter merk yang atas menampilkan kalau konsumen bisa berhubungan dengan merk, serta merk tersebut cocok dengan kebutuhan konsumen. (3) Asosiasi organisasi, yakni anggapan konsumen terhadap produsen produk. Dimensi asosiasi organisasi ialah perspektif merk bagaikan organisasi. Perspektif ini sangat berarti kala merk mempunyai atribut seragam yang menampilkan merk mewakili lebih dari hanya produk ataupun jasa (Chakraborty, 2019; Dwivedi et al., 2018).

\section{Brand Loyalty}

Brand loyalty yaitu keterikatan konsumen terhadap brand yang ditunjukkan oleh sikap dan perilaku konsumen. Sikap adalah bagaimana tingkat kepuasan konsumen terhadap suatu brand dan perilaku yaitu bagaimana keputusan konsumen untuk melakukan pembelian (Susilowati \& Sari, 2020). Brand loyalty adalah kecenderungan untuk secara positif membiaskan emosi, evaluasi dan/atau tanggapan perilaku dari alternatif atau pilihan merek. Konsumen biasanya membeli merek yang sama dari yang lain serta menggunakan dalam waktu yang lama (Chinomona \& Maziriri, 2017).

Konsumen dengan brand loyalty yang tinggi akan menghasilkan pembelian brand yang banyak dibandingkan dengan konsumen baru. Konsumen akan merasa terikat pada suatu brand dan hal ini membuat konsumen tidak sensitive terhadap harga. Brand loyalty konsumen yang tinggi akan menyebabkan konsumen memilih brand yang sama meskipun dibandingkan dengan brand yang lain (Yaseen \& Mazahir, 2019).

\section{Purchase intention}

Purchase intention atau hasrat membeli kembali mengacu pada mungkin ataupun kesempatan buat memakai kembali penyedia layanan tadinya dalam hasrat membeli kembali di masa mendatang, sebab pelanggan cenderung membeli barang atau jasa dari produsen yang cocok buat digunakan dalam waktu lama. Hasrat membeli kembali merupakan proses kesekian buat membeli benda serta jasa tertentu dari toko tertentu. Tidak hanya itu, hasrat beli kembali ialah elemen sikap, serta ada kemauan serta atensi yang konstan buat membeli benda ataupun merk. Hasrat beli ialah dimensi mungkin konsumen membeli produk. Terus menjadi besar hasrat beli hingga terus menjadi besar pula kemauan konsumen buat membeli benda. Sikap pembelian konsumen susah, sehingga umumnya diprediksi oleh hasrat beli. Oleh sebab itu, dianjurkan buat hasrat membeli, membolehkan pembelian serta pertimbangan pembelian bagaikan dimensi hasrat membeli (Chinomona \& Maziriri, 2017; Khan et al., 2014; Saputro \& Kurniawati, 2020). 


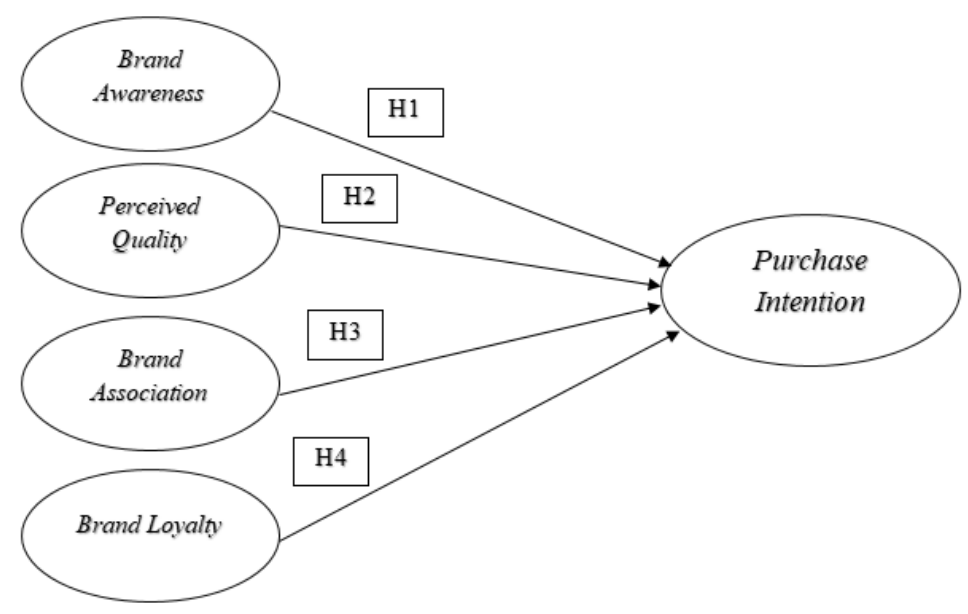

Gambar 1 : Rerangka Konseptual

Sumber:(Le-Hoang et al., 2020)

\section{Brand awareness dan Purchase intention}

Brand awareness membolehkan konsumen buat mengenali merk dari jenis produk yang berbeda ataupun dengan kata lain; pelanggan dapat mengingat dan menyadari merek. Selain itu, Brand awareness dapat secara aktif membantu konsumen dalam mengambil keputusan pembelian atau purchase intention. Di sisi lain, beberapa peneliti berpendapat bahwa Brand awareness mempunyai akibat yang signifikan terhadap purchase intention (Khan et,al., 2014). Merek termasuk dalam pertimbangan konsumen dan peningkatan pilihan. Brand awareness yang tinggi berdampak positif dan lebih cenderung mendorong perilaku pembelian (Susilowati \& Sari, 2020). Brand awareness dapat menunjukkan komitmen merek dan memotivasi pembeli untuk mempertimbangkan merek saat membeli, sehingga menarik minat purchase intention yang tinggi (Chakraborty, 2019; Khan et al., 2014). Hipotesis yang digunakan yaitu:

$\mathrm{H}_{1}$ : Brand awareness berpengaruh positif terhadap Purchase intention

\section{Perceived quality dan Purchase intention}

Perceived quality adalah perasaan pelanggan setelah mereka membeli produk atau jasa, dan mereka membandingkan dengan ekspektasi mereka (Horng et al., 2012). Ada hubungan positif antara persepsi kualitas dan purchase intention. Selain itu, bisnis yang memberikan layanan berkualitas tinggi memiliki keunggulan kompetitif dan dapat lebih menguntungkan karena mereka menyadari bahwa kualitas tinggi dapat memotivasi konsumen untuk lebih memilih merek tersebut daripada pesaing mereka (Hunt, 2019; Liu et al., 2017). Perceived quality seringkali memotivasi konsumen untuk membeli suatu produk dengan membedakan merek dari pesaing. Hipotesis yang digunakan yaitu:

$\mathrm{H}_{2}$ : Perceived quality berpengaruh positif terhadap Purchase intention

\section{Brand association dan Purchase intention}

Brand association adalah kekuatan yang diberikan oleh merek. Brand association bertindak sebagai alat pengumpulan informasi dan dapat membantu konsumen dalam mencari dan memproses informasi. Brand association yakni mengingat suatu merek (Chakraborty, 2019). Saat konsumen 
membeli produk atau menggunakan layanan, mereka perlu menyesuaikannya agar sesuai dengan Brand association seseorang atau ide konsumen tentang merek tersebut. Selain itu, Brand association memberikan pengaruh positif terhadap purchase intention konsumen pada produk (Susilowati \& Sari, 2020), karena sebagian besar Brand association berkaitan dengan atribut merek, pasar konsumen sasaran dan kebutuhan konsumen, sehingga menjadi dasar loyalitas merek. (Le-Hoang et al., 2020). Hipotesis yang digunakan yaitu:

$\mathrm{H}_{3}$ : Brand association berpengaruh positif terhadap Purchase intention

\section{Brand loyalty dan Purchase Intentention}

Brand loyalty adalah keterikatan yang dimiliki konsumen pada merek. Loyalitas pelanggan terhadap merek tidak mengevaluasi merek; mereka hanya perlu membeli produk dengan percaya diri (Çifci et al., 2016; Troiville et al., 2019). Oleh karena itu, ini menunjukkan komitmen pembeli potensial untuk membeli, sehingga mereka tidak berpaling ke merek pesaing. Pelanggan setia membeli merek favorit mereka secara teratur dan cenderung tidak berganti merek. Selain itu, pelanggan setia bersedia membayar lebih untuk merek tersebut. Brand loyalty mengacu pada pembelian secara berulang dan membeli lebih banyak dibandingkan dengan pembeli baru (Yaseen \& Mazahir, 2019). Oleh karena itu, brand loyalty besar dapat memfasilitasi sikap merk yang disukai dan membuat purchase intention pelanggan lebih tinggi (Tingchi Liu et al., 2012). Hipotesis yang digunakan yaitu:

$\mathrm{H}_{4}$ : Brand loyalty berpengaruh positif terhadap Purchase intention.

\section{METODE RISET}

\section{Rancangan Penelitian}

Studi yang dilakukan mengacu pada studi Le-Hoang et, al., (2020). Rancangan studi pada studi ini merupakan pengujian hipotesis, Hipotesis yang akan diuji adalah pengaruh antara brand awareness, perceived quality, brand association, brand loyalty terhadap purchase intention. Jenis data yang digunakan adalah cross sectional. Unit analisis studi ialah individual pelanggan minimarket Alfamart, Indomaret, dan Lawson di Jakarta.

\section{Metode Pengumpulan Data}

Data pada studi ini, memakai data primer yang didapatkan lewat penyebaran kuesioner dengan Google Form ke 200 responden konsumen minimarket Alfamart, Indomaret, Lawson di Jakarta yang melakukan pembelian minimun 6 Bulan terakhir. Metode yang digunakan dalam pegambilan sampel non-probability sampling pada studi ini memakai purposive sampling (Hermawan, 2013). Penelitian menggunakan skala likert dari 1 sangat tidak setuju (STT) hingga 5 sangat setuju (SS). Profil responden yang menjawab kuesioner pada studi ini yaitu: 
Rizkianti, H. \& Kurniawati. (2021). Determinan Purchase Intention: Perspektif ....

\begin{tabular}{|c|c|c|c|c|}
\hline \multirow{3}{*}{$\begin{array}{c}\text { No } \\
1\end{array}$} & \multirow{2}{*}{\multicolumn{2}{|c|}{ Keterangan }} & \multirow{3}{*}{$\begin{array}{c}\text { Frekuensi } \\
50\end{array}$} & \\
\hline & & & & \multirow{2}{*}{$\frac{\text { Persen }}{25,0}$} \\
\hline & Jenis Kelamin & Pria & & \\
\hline & & Wanita & 150 & 75,0 \\
\hline \multirow[t]{4}{*}{2} & Usia & 17-20 tahun & 42 & 21,0 \\
\hline & & 20-25 tahun & 131 & 65,5 \\
\hline & & 25-30 tahun & 18 & 9,0 \\
\hline & & $>30$ tahun & 9 & 4,5 \\
\hline \multirow[t]{5}{*}{3} & Jenjang Pendidikan & SMA/SMK & 26 & 13,0 \\
\hline & & Diploma & 76 & 38,0 \\
\hline & & S1 & 94 & 47 \\
\hline & & $\mathrm{S} 2$ & 4 & 2,0 \\
\hline & & S3 & 0 & 0 \\
\hline \multirow[t]{5}{*}{4} & Pekerjaan saat ini & Pelajar/Mahasiswa & 100 & 50,0 \\
\hline & & Karyawan Swasta & 66 & 33,0 \\
\hline & & PNS & 3 & 1,5 \\
\hline & & Wirausaha & 21 & 10,5 \\
\hline & & Lainnya & 10 & 0,5 \\
\hline \multirow[t]{4}{*}{5} & Pendapatan & Rp 500.000 - 1.000.000. & 75 & 37,5 \\
\hline & & $\operatorname{Rp} 1.000 .000-2.000 .000$ & 35 & 17,5 \\
\hline & & $\operatorname{Rp} 2.000 .000-3.000 .000$ & 26 & 13,0 \\
\hline & & $>\operatorname{Rp} 3.000 .000$ & 64 & 32,0 \\
\hline
\end{tabular}

Sumber: Hasil pengolahan data penulis

Berdasarkan Tabel 1 hasil dapat diketahui informasi deskriptif tentnag konsumen yaitu sebagian besar responden adalah wanita yaitu 50 responden, usia sebagian besar 20-25 tahun sebanyak 131 responden, jenjang pendidikan sebagian besar S1 sebanyak 94 responden, dengan pekerjaan sebagian besar Pelajar/Mahasiswa sebanyak 100 responden dan memiliki pendapatan sebagian besar Rp 500.000 - 1.000 .000 sebanyak 75 responden.

\section{Uji Validitas dan Reliabilitas}

Keputusan dalam uji validitas adalah membandingkan nilai factor loading dari setiap pernyataan dengan standard factor loading. Apabila jumlah sampel sebesar 200 responden, maka standard factor loading yang digunakan sebesar $(0,40)$. Jika faktor loading lebih dari 0,40 maka item pernyataan valid. Keputusan uji reliabilitas yaitu jika koefisien Cronbach's Alpha lebih besar dari 0,6 maka Cronbach's Alpha diterima (construct reliable).

Berdasarkan tabel 2. hasil uji validitas oleh variabel brand awareness, perceived quality, brand association, brand loyalty, dan purchase intention diperoleh nilai factor loading $\geq 0,40$ artinya tiap item pernyataan untuk mengukur variabel dinyatakan valid. Hasil uji reliabilitas dari variabel brand awareness, perceived quality, brand association, brand loyalty, dan purchase intention menujukkan nilai Cronbach's Alpha lebih besar dari 0,6 sehingga tiap instrument yang dipakai adalah reliabel 
Tabel 2. Hasil Uji Validitas dan Reliabilitas

\begin{tabular}{|c|c|c|c|}
\hline No & Variabel dan Pernyataan & $\begin{array}{l}\text { Nilai Factor } \\
\text { Loading }\end{array}$ & $\begin{array}{l}\text { Cronbach's } \\
\text { Alpha }\end{array}$ \\
\hline & Brand Awareness & & \multirow{5}{*}{0,635} \\
\hline 1 & Saya mengetahui slogan minimarket tersebut & 0,784 & \\
\hline 2 & Saya bisa mengenali warna karakteristik minimarket tersebut & 0,644 & \\
\hline 3 & $\begin{array}{l}\text { Ketika berpikir tentang berbelanja di minimarket, minimarket } \\
\text { tersebut pertama kali muncul di benak saya }\end{array}$ & 0,678 & \\
\hline 4 & $\begin{array}{l}\text { Informasi minimarket tersebut selalu diperbaharui di sosial } \\
\text { media seperti instagram, facebook, twitter }\end{array}$ & 0,658 & \\
\hline & Perceived Quality & & \multirow{8}{*}{0,847} \\
\hline 1 & $\begin{array}{l}\text { Merchandise minimarket tersebut memiliki kualitas yang } \\
\text { bagus }\end{array}$ & 0,686 & \\
\hline 2 & Minimarket tersebut memiliki tempat yang bersih & 0,589 & \\
\hline 3 & $\begin{array}{l}\text { Barang yang dijual minimarket tersebut memiliki harga yang } \\
\text { terjangkau }\end{array}$ & 0,757 & \\
\hline 4 & Staff minimarket tersebut ramah dan antusias & 0,711 & \\
\hline 5 & Minimarket tersebut memiliki barang yang lengkap & 0,767 & \\
\hline 6 & Minimarket tersebut memiliki toilet yang bersih & 0,777 & \\
\hline 7 & Minimarket tersebut memiliki tempat parkir yang aman & 0,772 & \\
\hline & Brand Association & & \multirow{5}{*}{0,790} \\
\hline 1 & $\begin{array}{l}\text { Saya dapat menemukan barang kebutuhan sehari-hari yang } \\
\text { saya butuhkan di minimarket tersebut }\end{array}$ & 0,827 & \\
\hline 2 & $\begin{array}{l}\text { Saat menyebut minimarket, saya segera ingat minimarket } \\
\text { tersebut }\end{array}$ & 0,734 & \\
\hline 3 & $\begin{array}{l}\text { Minimarket tersebut memiliki banyak program layanan } \\
\text { pelanggan }\end{array}$ & 0,851 & \\
\hline 4 & $\begin{array}{l}\text { Minimarket tersebut menawarkan banyak keuntungan dalam } \\
\text { membeki barang yang dijual }\end{array}$ & 0,727 & \\
\hline & Brand Loyalty & & \multirow{5}{*}{0,867} \\
\hline 1 & $\begin{array}{l}\text { Saya akan berbicara hal baik mengenai minimarket tersebut } \\
\text { kepada semua orang }\end{array}$ & 0,809 & \\
\hline 2 & Seterusnya saya akan berbelanja di minimarket tersebut & 0,888 & \\
\hline 3 & $\begin{array}{l}\text { Saya akan tetap berbelanja di minimarket tersebut meskipun } \\
\text { pesaing lain memiliki keunggulan }\end{array}$ & 0,869 & \\
\hline 4 & $\begin{array}{l}\text { Saya dan keluarga memilih minimarket tersebut jika ingin } \\
\text { berbelanja }\end{array}$ & 0,825 & \\
\hline & Purchase Intention & & \multirow{4}{*}{0,881} \\
\hline 1 & Saya akan membeli barang di minimarket tersebut & 0,890 & \\
\hline 2 & $\begin{array}{l}\text { Saya berniat untuk terus memilih minimarket tersebut untuk } \\
\text { berbelanja }\end{array}$ & 0,903 & \\
\hline 3 & $\begin{array}{l}\text { Saya akan merekomendasikan minimarket tersebut kepada } \\
\text { teman dan keluarga untuk berbelanja }\end{array}$ & 0,912 & \\
\hline
\end{tabular}

Sumber: Hasil Penelitian Terlampir.

\section{HASIL PENELITIAN DAN PEMBAHASAN}

\section{Uji Kesesuaian Model (Goodness Of Fit Model)}

Dalam menguji nilai goodness of fit dilakukan dengan melihat kriteria pengukurannya. (1) Absolute fit measure, (2) Incremental fit measure, (3) Parsimonious fit measure. Berdasarkan hasil Uji Kesesuaian Model (Goodness of fit) pada tabel 3, keseluruhan model yang digunakan menghasilkan tingkat kesesuaian dan penerimaan model yang baik karena cukup memenuhi kriteria dari indikator kesesuaian model. 
Rizkianti, H. \& Kurniawati. (2021). Determinan Purchase Intention: Perspektif ....

Tabel 3. Hasil Uji Kesesuaian Model (Goodness of fit)

\begin{tabular}{ccccc}
\hline Jenis Pengukuran & Pengukuran & Nilai & $\begin{array}{c}\text { Batas penerimaan yang } \\
\text { disarankan }\end{array}$ & Kesimpulan \\
\hline Absolute fit & $p$ & 0,000 & $\geq 0,05$ & Poor Fit \\
measures & GFI & 0,837 & $\geq 0,09$ & Poor Fit \\
& RMSEA & 0,081 & $\geq 0,08$ & Goodness of Fit \\
Incremental fit & AGFI & 0,783 & $\geq 0,90$ atau mendekati 1 & Poor Fit \\
measures & TLI & 0,878 & $\geq 0,95$ atau mendekati 1 & Marginal Fit \\
Parsimonius fit & CFI & 0,899 & $\geq 0,95$ atau mendekati 1 & Marginal Fit \\
measures & CMIN/DF & 2,294 & Batas bawah 1. Batas atas 3 & Goodness of Fit \\
& CMIN & 435,814 & Diharapkan nilai kecil & Goodness of Fit \\
\hline \multicolumn{5}{c}{ Sumber: Hasil pengolahan data penulis }
\end{tabular}

\section{Uji Hipotesis}

Hasil pengujian hipotesis menggunakan teknik analisis SEM:

Tabel 4. Hasil Uji Hipotesis

\begin{tabular}{lccc}
\hline \multicolumn{1}{c}{ Hipotesis } & Estimate & p-Value & Keputusan \\
\hline $\begin{array}{l}\text { Tidak terdapay pengaruh positif brand awareness terhadap } \\
\text { purchase intention }\end{array}$ & 0,113 & 0,316 & $\begin{array}{c}\text { Ho gagal } \\
\text { ditolak }\end{array}$ \\
$\begin{array}{l}\text { Tidak terdapay pengaruh positif perceived quality terhadap } \\
\text { purchase intention }\end{array}$ & 0,087 & 0,627 & $\begin{array}{c}\text { Ho gagal } \\
\text { ditolak }\end{array}$ \\
$\begin{array}{l}\text { Tidak terdapay pengaruh positif brand association terhadap } \\
\text { purchase intention }\end{array}$ & 0,431 & 0,000 & Ho ditolak \\
$\begin{array}{l}\text { Tidak terdapay pengaruh positif brand loyaty terhadap } \\
\text { purchase intention }\end{array}$ & 0,352 & 0,004 & Ho ditolak \\
\hline
\end{tabular}

Sumber: Hasil Penelitian Terlampir

Berdasarkan hasil penelitian dapat disimpul $\mathrm{H} 1$ pengaruh brand awareness terhadap purchase intention ditunjukkan dengan dengan nilai p-value sebesar 0,316 dan estimate 0,113 , hipotesis tidak di dukung. $\mathrm{H} 2$ pengaruh perceived quality terhadap purchase intention ditunjukkan dengan nilai $p$-value sebesar 0,627 dan estimate 0,087, hipotesis tidak didukung. H3 pengaruh brand association terhadap purchase intention signifikan ditampilkan dengan nilai p-value sebesar 0,000 dan estimate 0,431 . H4 pengaruh brand loyalty terhadap purchase intention signifikan ditunjukkan dengan nilai $p$-value sebesar 0,004 dan estimate 0,352 . Hasil dari empat (4) hipotesis yang diajukan hanya dua hipotesis yang didukung dan dua lainnya tidak didukung karena hasil nilai p-value lebih besar dari 0,05.

\section{KESIMPULAN DAN SARAN}

Dari hasil riset serta ulasan bisa disimpulkan $\mathrm{H} 1$ menyatakan brand awareness mempengaruhi positif terhadap purchase intention ternyata hipotesis tersebut tidak didukung, H2 menyatakan perceived quality mempengaruhi positif terhadap purchase intention ternyata hipotesis tersebut tidak didukung, H3 menyatakan brand association berpengaruh positif terhadap purchase intention dan hipotesis tersebut didukung, $\mathrm{H} 4$ menyatakan brand loyaty berpengaruh positif terhadap purchase intention dan hipotesis tersebut didukung. 


\section{Keterbatasan Penelitian}

Terdapat sebagian keterbatasan yang dirasakan peneliti ialah objek penelitian cuma di fokusnya pada minimarket di Jakarta. Berikutnya jawaban yang diberikan oleh responden tidak senantiasa menampilkan kondisi yang sebetulnya.

\section{Saran}

1. Untuk Minimarket Alfamart, Indomaret, Lawson

Implikasi manajerial yang dapat menjadi masukan untuk perusahaan Alfamart, Indomaret, Lawson buat menaikkan brand awareness dan perceived quality dari konsumen, yaitu sebagai berikut: (1) melakukan strategi pemasaran melalui sosial media, advertising melalui TV, Banner, mengenai slogan minimarket agar konsumen lebih mengenal keberadaan slogan minimarket. (2) melakukan banyakan program hubungan dengan masyarakat, sehingga citra merek minimarket lebih baik dalam benak konsumen. (3) Menjalankan kegiatan untuk pembersihan toilet dan fasilitas di minimarket secara rutin, agar pelanggan merasa nyaman ketika berkunjung ke minimarket.

2. Untuk Minimarket Alfamart, Indomare, Lawson

Penelitian selanjutnya dapat menambahkan variabel bebas dari dimensi brand equity yaitu brand protection. Peneliti selanjutnya diharapkan dapat memperluas cakupan penelitian di berbagai jenis bisnis tidak hanya minimarket. 


\section{DAFTAR PUSTAKA}

Atulkar, S. (2020). Brand trust and brand loyalty in mall shoppers. Marketing Intelligence and Planning. 38(5), 559-572. https://doi.org/10.1108/MIP-02-2019-0095

Chakraborty, U. (2019). The impact of source credible online reviews on purchase intention: The mediating roles of brand equity dimensions. Journal of Research in Interactive Marketing, 13(2), 142-161. https://doi.org/10.1108/JRIM-06-2018-0080

Chinomona, R., \& Maziriri, E. T. (2017). The influence of brand awareness, brand association and product quality on brand loyalty and repurchase intention: A case of male consumers for cosmetic brands in South Africa. Journal of Business and Retail Management Research, 12(1), 143-154. https://doi.org/10.24052/jbrmr/v12is01/tiobabaapqoblariacomcfcbisa

Cifci, S., Ekinci, Y., Whyatt, G., Japutra, A., Molinillo, S., \& Siala, H. (2016). A cross validation of Consumer-Based Brand Equity models: Driving customer equity in retail brands. Journal of Business Research, 69(9), 3740-3747. https://doi.org/10.1016/j.jbusres.2015.12.066

Dwivedi, A., Nayeem, T., \& Murshed, F. (2018). Brand experience and consumers willingness-to-pay (WTP) a price premium: Mediating role of brand credibility and perceived uniqueness. Journal of Retailing and Consumer Services, 44(June), 100-107. https://doi.org/10.1016/j.jretconser.2018.06.009

Gil-Saura, I., Ruiz-Molina, M. E., Michel, G., \& Corraliza-Zapata, A. (2013). Retail brand equity: A model based on its dimensions and effects. International Review of Retail, Distribution and Consumer Research, 23(2), 111-136. https://doi.org/10.1080/09593969.2012.746716

Gumiwang, R. (2019). alfamart-vs-indomaret-siapa-lebih-pesat-dlvo. https://tirto.id/alfamart-vsindomaret-siapa-lebih-pesat-dlvo

Hermawan, A. (2013). Penelitian Bisnis: Pendekatan Kuantitatif dan Metode Campuran.

Horng, J. S., Liu, C. H., Chiu, H. Y., \& Tsai, C. Y. (2012). The role of international tourist perceptions of brand equity and travel intention in culinary tourism. Service Industries Journal, 32(16), 26072621. https://doi.org/10.1080/02642069.2011.594879

Hunt, S. D. (2019). The ethics of branding, customer-brand relationships, brand-equity strategy, and branding as a societal institution. Journal of Business Research, 95(May), 408-416. https://doi.org/10.1016/j.jbusres.2018.07.044

Khan, N., Rahmani, S. H. R., Hoe, H. Y., \& Chen, T. B. (2014). Causal Relationships among Dimensions of Consumer-Based Brand Equity and Purchase intention: Fashion Industry. International Journal of Business and Management, 10(1), 172-181. https://doi.org/10.5539/ijbm.v10n1p172

Le-Hoang, P. V., Nguyen, G. T., Phung, H. T. T., Ho, V. T., \& Phan, N. T. (2020). The relationship between brand equity and intention to buy: the case of convenience stores. Independent Journal of Management \& Production, 11(2), 434. https://doi.org/10.14807/ijmp.v11i2.1062 
Lin, J., Lobo, A., \& Leckie, C. (2017). The role of benefits and transparency in shaping consumers green perceived value, self-brand connection and brand loyalty. Journal of Retailing and Consumer Services, 35(December 2016), 133-141. https://doi.org/10.1016/j.jretconser.2016.12.011

Liu, M. T., Wong, I. K. A., Tseng, T. H., Chang, A. W. Y., \& Phau, I. (2017). Applying consumerbased brand equity in luxury hotel branding. Journal of Business Research, 81(January), 192202. https://doi.org/10.1016/j.jbusres.2017.06.014

Rubio, N., Villasenor, N., \& Yague, M. J. (2017). Creation of consumer loyalty and trust in the retailer through store brands: The moderating effect of choice of store brand name. Journal of Retailing and Consumer Services, 34, 358-368. https://doi.org/10.1016/j.jretconser.2016.07.014

Saputro, D. B., \& Kurniawati. (2020). No Title. The Determinant of Intention to Purchase, Volume 24(Issue 3), 752-764.

Sasmita, J., \& Mohd Suki, N. (2015). Young consumers insights on brand equity: Effects of brand association, brand loyalty, brand awareness, and brand image. International Journal of Retail and Distribution Management, 43(3), 276-292. https://doi.org/10.1108/IJRDM-02-2014-0024

Susilowati, E., \& Sari, A. N. (2020). Independent Journal of Management \& Production (Ijm\&P). February, 39-53. https://doi.org/10.14807/ijmp.v

Tingchi Liu, M., Chu, R., Wong, I. A., Angel Zuniga, M., Meng, Y., \& Pang, C. (2012). Exploring the relationship among affective loyalty, perceived benefits, attitude, and intention to use co-branded products. Asia Pacific Journal of Marketing and Logistics, 24(4), 561-582. https://doi.org/10.1108/13555851211259025

Tristiawati, P. (2019). alfamart-raup-pendapatan-rp-6682-triliun-sepanjang-2018 @ www.liputan6.com. https://www.liputan6.com/bisnis/read/3968109/alfamart-raup-pendapatanrp-6682-triliun-sepanjang-2018

Troiville, J., Hair, J. F., \& Cliquet, G. (2019). Definition, conceptualization and measurement of consumer-based retailer brand equity. Journal of Retailing and Consumer Services, 50(April), 73-84. https://doi.org/10.1016/j.jretconser.2019.04.022

Yaseen, S., \& Mazahir, I. (2019). Impact of Corporate Credibility, Brand awareness, Brand Image and Brand loyalty on Purchase intention in the Telecommunication Sector of Karachi. Global Management Journal for Academic \& Corporate Studies, 9(1), 86-99. http://eserv.uum.edu.my/docview/2264570935?accountid=42599 
Rizkianti, H. \& Kurniawati. (2021). Determinan Purchase Intention: Perspektif ....

\section{LAMPIRAN}

\begin{tabular}{|c|c|c|c|}
\hline No & Item Pernyataan & Mean & $\begin{array}{l}\text { Cronbach's } \\
\text { Alpha }\end{array}$ \\
\hline & Brand Awareness & & \\
\hline 1 & Saya mengetahui slogan minimarket tersebut & 4,2700 & 0,90064 \\
\hline 2 & Saya bisa mengenali warna karakteristik minimarket tersebut & 4,6150 & 0,57308 \\
\hline 3 & $\begin{array}{l}\text { Ketika berpikir tentang berbelanja di minimarket, minimarket } \\
\text { tersebut pertama kali muncul di benak saya }\end{array}$ & 4,4200 & 0,66770 \\
\hline \multirow[t]{2}{*}{4} & $\begin{array}{l}\text { Informasi minimarket tersebut selalu diperbaharui di sosial } \\
\text { media seperti instagram, facebook, twitter }\end{array}$ & 4,3450 & 0,61471 \\
\hline & Perceived Quality & & \\
\hline 1 & $\begin{array}{l}\text { Merchandise minimarket tersebut memiliki kualitas yang } \\
\text { bagus }\end{array}$ & 3,9250 & 0,83237 \\
\hline 2 & Minimarket tersebut memiliki tempat yang bersih & 4,2800 & 0,59445 \\
\hline 3 & $\begin{array}{l}\text { Barang yang dijual minimarket tersebut memiliki harga yang } \\
\text { terjangkau }\end{array}$ & 3,9150 & 0,76859 \\
\hline 4 & Staff minimarket tersebut ramah dan antusias & 4,0600 & 0,68465 \\
\hline 5 & Minimarket tersebut memiliki barang yang lengkap & 3,9900 & 0,83663 \\
\hline 6 & Minimarket tersebut memiliki toilet yang bersih & 3,6550 & 1,04472 \\
\hline \multirow[t]{2}{*}{7} & Minimarket tersebut memiliki tempat parkir yang aman & 3,9500 & 0,86675 \\
\hline & Brand Association & & \\
\hline 1 & $\begin{array}{l}\text { Saya dapat menemukan barang kebutuhan sehari-hari yang } \\
\text { saya butuhkan di minimarket tersebut }\end{array}$ & 4,1250 & 0,64143 \\
\hline 2 & $\begin{array}{l}\text { Saat menyebut minimarket, saya segera ingat minimarket } \\
\text { tersebut }\end{array}$ & 4,1700 & 0,73744 \\
\hline 3 & $\begin{array}{l}\text { Minimarket tersebut memiliki banyak program layanan } \\
\text { pelanggan }\end{array}$ & 3,9700 & 0,73608 \\
\hline \multirow[t]{2}{*}{4} & $\begin{array}{l}\text { Minimarket tersebut menawarkan banyak keuntungan dalam } \\
\text { membeki barang yang dijual }\end{array}$ & 3.9850 & 0,71226 \\
\hline & Brand Loyalty & & \\
\hline 1 & $\begin{array}{l}\text { Saya akan berbicara hal baik mengenai minimarket tersebut } \\
\text { kepada semua orang }\end{array}$ & 3,9900 & 0,75681 \\
\hline 2 & Seterusnya saya akan berbelanja di minimarket tersebut & 3,9400 & 0,87764 \\
\hline 3 & $\begin{array}{l}\text { Saya akan tetap berbelanja di minimarket tersebut meskipun } \\
\text { pesaing lain memiliki keunggulan }\end{array}$ & 3,7600 & 0,99365 \\
\hline \multirow[t]{2}{*}{4} & $\begin{array}{l}\text { Saya dan keluarga memilih minimarket tersebut jika ingin } \\
\text { berbelanja }\end{array}$ & 3,8850 & 0,94139 \\
\hline & Purchase Intention & & \\
\hline 1 & Saya akan membeli barang di minimarket tersebut & 4,0900 & 0,71727 \\
\hline 2 & $\begin{array}{l}\text { Saya berniat untuk terus memilih minimarket tersebut untuk } \\
\text { berbelanja }\end{array}$ & 3,8400 & 0,91575 \\
\hline 3 & $\begin{array}{l}\text { Saya akan merekomendasikan minimarket tersebut kepada } \\
\text { teman dan keluarga untuk berbelanja }\end{array}$ & 3.9400 & 0,83057 \\
\hline
\end{tabular}

